Strategies for Developing and Sustaining Patient and Community Advisory Groups: Lessons from the State Networks of Colorado Ambulatory Practices and Partners (SNOCAP) Consortium of PracticeBased Research Networks

\author{
Mary Fisher, MPH, Sarah E. Brewer, MPA, John M. Westfall, MD, MPH, \\ Matthew Simpson, MD, MPH, Linda Zittleman, MSPH, Sean T. O'Leary, MD, MPH, \\ Douglas H. Fernald, MA, Andrea Nederveld, MD, MPH, and Donald E. Nease, Jr, MD
}

Background: Patient and community engagement is essential to maintain the relevance of practicebased research. Empowered engagement requires going beyond the check box, with advisory groups involved in every aspect of a project. Here, 4 Colorado practice-based research networks (PBRNs) share their advisory group origins, as well as methods for continued engagement and the work that has resulted.

Methods: PBRNs, like communities and practices, vary in form and function. In a 4-part case series, we describe commonalities and differences among advisory groups within the State Networks of Colorado Ambulatory Practices and Partners (SNOCAP), a consortium of PBRNs in Colorado. Three SNOCAP advisory groups are well established, while a fourth is under development.

Results: Each case shares ways in which advisory groups have been structured within SNOCAP, including meeting frequency, compensation, and member activities to ensure the design, conduct, analysis, and dissemination of research are grounded in the needs of patients and communities. We share 6 lessons learned regarding membership, relationships, relevance, care and feeding, listening, and showing up.

Conclusions: SNOCAP believes advisory groups are the backbone and guidepost of PBRN work. Patient advisors are an essential and invaluable complement to traditional research when engaged beyond "basic" participation. Best structures for advisory groups depend upon stakeholder needs. (J Am Board Fam Med 2019;32:663-673.)

Keywords: Colorado, Community Medicine, Community Networks, Patient Participation, Practice-based Research, Primary Health Care

The argument has been made that "practice-based research is community engagement." Rigorous stakeholder engagement fosters collaborative partnerships in all phases of research by promoting

This article was externally peer reviewed.

Submitted 25 January 2019; revised 31 May 2019; accepted 14 June 2019.

From the Department of Family Medicine, University of Colorado, Aurora, CO (MF, SEB, JMW, MS, LZ, DHF, AN, DEN); Adult and Child Consortium for Health Outcomes Research and Delivery Science, Aurora, CO (SEB, STO, DEN); Department of Pediatrics, University of Colorado, Aurora, CO (STO).

Funding: none. colearning and an empowering environment that facilitates reciprocal transfer of knowledge, skills, and power. Patient and community engagement in research is shown to enhance the relevance of research projects, ${ }^{2}$ bridge existing cultural gaps, ${ }^{3,4}$ increase the translation of evidence-based interventions, ${ }^{5}$ and promote greater sustainability of these interventions. ${ }^{6}$ Sustained engagement involves a

Conflict of interest: none declared.

Corresponding author: Mary Fisher, Department of Family Medicine, University of Colorado, 13199 E, Montview Blvd, Suite 210, Aurora, CO 30045. (E-mail: mary.fisher@ cvanschutz.edu). 
Table 1. SNOCAP Advisory Groups, History, Membership, and Staffing

\begin{tabular}{|c|c|c|c|c|c|c|}
\hline $\begin{array}{l}\text { SNOCAP } \\
\text { Network }\end{array}$ & $\begin{array}{c}\text { Advisory Group } \\
\text { Name }\end{array}$ & $\begin{array}{l}\text { Practice Type/ } \\
\text { Location }\end{array}$ & $\begin{array}{l}\text { PBRN } \\
\text { Founded }\end{array}$ & $\begin{array}{l}\text { Year Advisory } \\
\text { Group } \\
\text { Started }\end{array}$ & $\begin{array}{l}\text { Members in } \\
\text { Advisory Group }\end{array}$ & Staffing \\
\hline HPRN & C.A.C. & $\begin{array}{l}\text { Rural; Eastern } \\
\text { Colorado }\end{array}$ & 1997 & 2003 & $15+5$ staff & $\begin{array}{l}\text { Director, co-director, plus } \\
3 \text { local practice } \\
\text { facilitators/ liaisons }\end{array}$ \\
\hline CaReNet & PAC & $\begin{array}{l}\text { Federally Qualified } \\
\text { Health Centers } \\
\text { and Family } \\
\text { Medicine } \\
\text { Residency } \\
\text { Locations; front } \\
\text { range and San } \\
\text { Luis Valley }\end{array}$ & 1998 & 2004 & $13+3$ staff & $\begin{array}{l}\text { Director, co-director, } \\
\text { coordinator }\end{array}$ \\
\hline COCONet & NAB & $\begin{array}{l}\text { Pediatric and child } \\
\text { health focused } \\
\text { practices; } \\
\text { statewide }\end{array}$ & 2011 & 2016 & $13+2$ staff & $\begin{array}{l}\text { Director, associate } \\
\text { director }\end{array}$ \\
\hline PEACHnet & RAB & $\begin{array}{l}\text { Rural; Western } \\
\text { Colorado }\end{array}$ & 2017 & 2019 & $\begin{array}{l}\text { Up to } 10 \text { members } \\
\text { recruited in } \\
2019+2 \text { staff }\end{array}$ & $\begin{array}{l}\text { Director, professional } \\
\text { research assistant }\end{array}$ \\
\hline
\end{tabular}

C. A. C., Community Advisory Council; CaReNet, Colorado Research Network; COCONet, Colorado Children's Outcomes Network; HPRN, High Plains Research Network; NAB, Network Advisory Board; PAC, Patient Advisory Council; PBRN, Practice-based Research Network; PEACHnet, Partners Engaged in Achieving Change in Health; RAB, Regional Advisory Board; SNOCAP, State Networks of Colorado Ambulatory Practices and Partners.

cyclic and iterative process. Therefore, patients and community members involved in well-structured practice-based research networks (PBRN) research, and research with a strong engagement lens, ${ }^{4,7}$ often serve as advisory group members to make longterm contributions to research operations.

Participatory research builds long-term relationships that outlast any specific research project; these relationships form the foundation of a sustained conversation that includes bidirectional communication and collaborative decision making. At its core, participatory research is conducting research with a community, however defined, rather than simply in a community or for a community. ${ }^{1}$ Research with a community requires engaging members as partners in all phases of the research. Moving participation along a continuum from informing through empowering helps "increase impact on the decision" and creates a higher level of participation and engagement. ${ }^{8}$ Participatory research is the "systematic enquiry, with the collaboration of those affected by the issue under study, for the purpose of education and taking action or effecting social change." 1

A 2006 survey found that 24\% of PBRNs included community members in their PBRN advisory structures. ${ }^{9}$ In an accompanying editorial, Macaulay and Nutting ${ }^{10}$ called for more incorporation of commu- nity-based participatory research into PBRNs. Beginning in the early 2000s, Colorado's PBRNs, under the State Networks of Colorado Ambulatory Practices and Partners (SNOCAP) consortium, started forming patient and community advisory groups. The structures for each group vary, but are equally purposeful. In this article we share the Colorado story of building, growing, and maintaining 4 PBRN advisory groups and begin distilling lessons learned for other PBRNs.

\section{Methods: Case Series}

Tapp and Dulin ${ }^{11}$ have created a theoretical process for how community advisory groups could function within a PBRN infrastructure; many recommendations have been incorporated by SNOCAP. Here, we showcase advisory group structures as a series of cases within 4 different PBRNs. SNOCAP staff gathered historic records and member data to complete each case. Table 1 presents a brief overview of the structure of each group. Table 2 shares themes similar among 3 of the advisory groups. Table 3 shows the wide range of topics each advisory group has addressed, or is currently working on. The 4 cases presented below are organized into history and origins, member recruitment, engagement in research projects, ongoing engagement, and impact. 

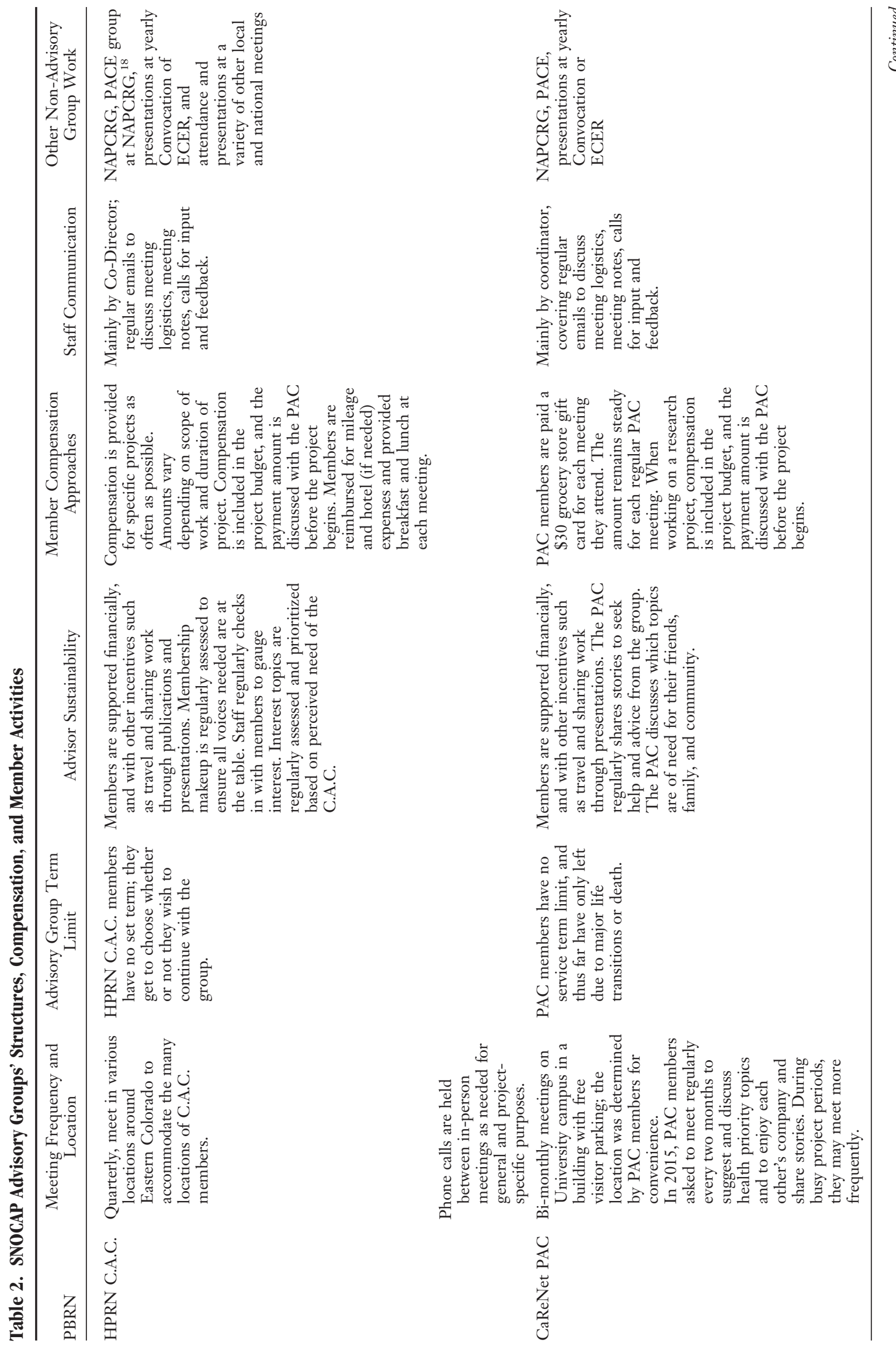


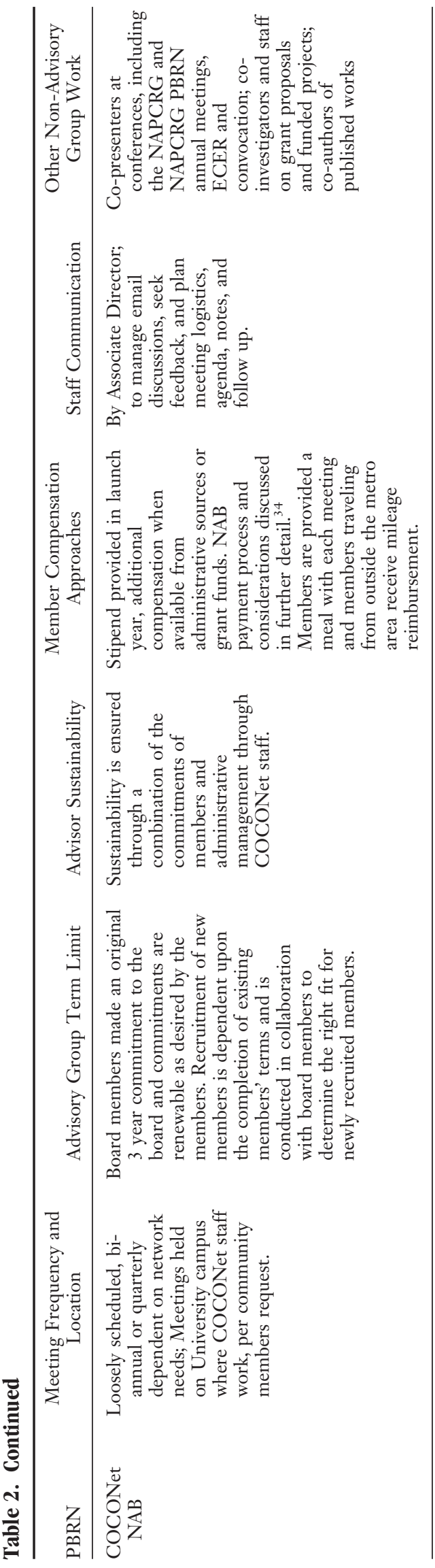

\begin{tabular}{|c|c|c|}
\hline$\approx$ & $\begin{array}{l}\text { PBRN Advisory } \\
\text { Group }\end{array}$ & Projects \\
\hline & \multirow[t]{13}{*}{ HPRN CAC } & Colorectal Cancer Screening \\
\hline & & Asthma \\
\hline & & High blood pressure home monitoring \\
\hline & & PCMH \\
\hline$=$ & & High risk assessments \\
\hline 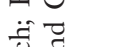 & & Methamphetamine \\
\hline & & Hypertension \\
\hline & & Behavioral Health \\
\hline $2=$ & & Mental Health \\
\hline$\stackrel{\Xi}{\tilde{j}}$ & & $\begin{array}{l}\text { Preventing mental, emotional, and } \\
\text { behavioral issues in youth }\end{array}$ \\
\hline 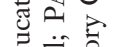 & & Chronic Obstructive Pulmonary Disease \\
\hline$\frac{8}{\sum_{0}^{0}}$ & & $\begin{array}{l}\text { Medication Assisted Treatment for } \\
\text { Opioid Use Disorder }\end{array}$ \\
\hline & & SBIRT \\
\hline & \multirow[t]{6}{*}{ CaReNet PAC } & Diabetes \\
\hline 已ं & & $\begin{array}{l}\text { Improvement in physical activity and } \\
\text { healthy eating }\end{array}$ \\
\hline ن्र & & Tobacco Cessation Counseling \\
\hline & & Patient Safety \\
\hline & & Chronic Pain \\
\hline & & Dementia/Alzheimer's \\
\hline 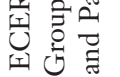 & \multirow[t]{3}{*}{$\begin{array}{l}\text { COCONet } \\
\text { NAB }\end{array}$} & $\begin{array}{l}\text { Training care advocates, to improve } \\
\text { health outcomes }\end{array}$ \\
\hline c: & & Mental Health care access \\
\hline 馬 & & Immunization refusal \\
\hline$\stackrel{2}{\simeq}$ & \multirow[t]{2}{*}{$\begin{array}{l}\text { PEACHnet } \\
\text { RAB }\end{array}$} & $\begin{array}{l}\text { Intersection of diabetes, obesity, and } \\
\text { mental health }\end{array}$ \\
\hline$\stackrel{?}{\stackrel{0}{*}}$ & & Food insecurity \\
\hline
\end{tabular}

CAC, Community Advisory Council; CaReNet, Colorado Research Network; COCONet, Colorado Children's Outcomes Network; HPRN, High Plains Research Network; NAB, Network Advisory Board; PAC, Patient Advisory Council; PBRN, Practice-based research network; PCMH, Patient-Centered Medical Home; PEACHnet, Partners Engaged in Achieving Change in Health; RAB, Regional Advisory Board; SBIRT, Screening, Brief Intervention, Referral to Treatment.

Convocation: this is a small state-wide conference of PBRN and CTSA Engagement core stakeholders held bi-annually in the Denver area.

ECER: Engaging Communities in Education and Researchthis is a state-wide conference of health professionals, rural preceptors, PBRN members, and community/patient partners held bi-annually in Colorado. ${ }^{16}$

\section{Case Studies}

High Plains Research Network's Community Advisory

Council

History and Origins. High Plains Research Network (HPRN) aspires to full community, patient, and provider participatory research, ${ }^{1}$ and has worked to actively engage providers and practices in the network since 1997. Shortly after inception, 
HPRN leaders realized a set of crucial voices were missing for truly relevant research in rural communities. ${ }^{9}$ After studying the principles of communitybased participatory research, leadership began creating a Community Advisory Council (C.A.C.). Since 2003, an active C.A.C. of local farmers, ranchers, school teachers, business owners, and students grounds research in real patient experience. ${ }^{12}$

C.A.C. Member Recruitment. Community members were originally identified by local physicians, public health professionals, hospital administrators, and through discussions with local community members; HPRN staff cold called local residents and conducted conversations to discuss HPRN's work. Potential participants inquired about the purpose, logistics of meetings and activities, and wanted assurance that they could truly impact HPRN's work. Now, after nearly 16 years together, the group continues to annually discuss voices missing at the table, providing the opportunity to identify new voices needed. For example, early on the group realized the need for youth; now every 2 years the HPRN identifies local high school students for participation.

\section{C.A.C. Engagement in Research Projects. HPRN} research topics require a balance between community and funder priorities. Before the C.A.C., research was mostly driven by the Director, ${ }^{13} \mathrm{HPRN}$ providers, ${ }^{14}$ and funding opportunities. After the C.A.C. formed, research began moving to the interface between clinics and community. ${ }^{15}$ During the first year, the C.A.C. developed a "top 10" list of priorities. Over the next 10 years, HPRN attempted to develop research related to these topics. Sometimes a funding opportunity topic arose that was not on the list. In those instances, the C.A.C. determined if they were interested in the topic. In 1 case, the C.A.C. rejected a project led by an urban University professor recruiting community for a healthy eating study. Part of the study included use of a recipe book. The first recipe was fresh trout with mango, neither of which are available in eastern Colorado. The C.A.C. encouraged the investigator to come back before the next grant so they could help codevelop a meaningful research project.

Funding for C.A.C. priorities was not always available. For example, methamphetamine abuse, a priority the C.A.C. applied for, was left unfunded after 3 unsuccessful submissions. In the first 10 years, the HPRN addressed 7 of the original 10 topics.

Ongoing Engagement. During an annual conference, called in alternating years SNOCAP Convocation or Engaging Communities in Education and Research (ECER), ${ }^{16}$ the HPRN C.A.C. periodically holds retreats to update their priority list. Topics on this list are considered first; however, the C.A.C. also considers projects presented by both University of Colorado researchers, and collaborations with other institutions. For each project, the C.A.C. may be joined by other stakeholders such as local health professionals, affected patients, students, and community leaders.

Additional engagement activities for the C.A.C include engagement as coinvestigators on grants ${ }^{17}$ and registration for attendance to the North American Primary Care Research Group's (NAPCRG) Annual Conference. ${ }^{18}$ The HPRN staff is dedicated to regular communication between C.A.C. meetings, as seen in Table 2. Most importantly, the C.A.C. and HPRN staff feel that by sharing stories and personal interests, relationships are further developed and participatory work is strengthened.

Impact. The C.A.C. has led the development of all aspects of projects and assisted with data collection, analysis, interpretation, and dissemination of findings. ${ }^{15,19-22}$ For many topics, the C.A.C. undertakes a process called Boot Camp Translation (BCT) with the goal of translating medical jargon into locally relevant, actionable messages and materials. $^{23}$ BCT has become an evidence-based method for engaging community in meaningful long-term participatory research. ${ }^{21}$

C.A.C. members are active in the interpretation and dissemination results. ${ }^{22}$ As data are analyzed, C.A.C. members interpret results, address community impact, and seek additional analysis. Previously, they worked with the Colorado Multi-Institutional Review Board on the approach to projects with patients and community members as coresearchers. ${ }^{17}$ C.A.C. members have authored and coauthored many articles. ${ }^{15,22-25}$ As 1 farmer and C.A.C. member put it, "as long as the research is helping my community, I will participate. As soon as this becomes about the researcher or the University, I am out of here." This is known as the Garry Haynes ethic, named after the farmer, and serves as the guidepost for the work of the HPRN and C.A.C. 
Colorado Research Network's Patient Advisory Council

History and Origins. Colorado Research Network (CaReNet) is a PBRN focused on Federally-Qualified Health Centers and Family Medicine Residency sites. Patient Advisory Council (PAC) members live and work in the Denver metro area. The PAC was originally formed in 2010 in conjunction with a diabetes project. ${ }^{26,27}$ Members were invited to serve as patient experts, fully involved in research processes. The mission of the PAC is to bring together patients from $\mathrm{CaReNet}$ practices to advise and guide projects from inception to dissemination. PAC Member Recruitment. Original PAC members were referred by physicians, clinic staff, and direct outreach by other potential members. The group expanded through snowball sampling, ${ }^{28}$ where current PAC members share contacts they think would be a good fit based on group needs. Currently the PAC consists mainly of retired professionals from a variety of fields: engineering, education, sales, nursing, accounting, real estate, and government. Spouses are often recruited to the PAC; CaReNet staff encourages this participation, as it allows for members to engage in further discussion between meetings, or for one to miss a meeting and later engage in conversation with their partner.

PAC Engagement in Research Projects. When the original diabetes project concluded, participants were invited to continue engagement. All group members chose to continue work on future projects. The PAC has participated throughout the full life cycle of projects. They regularly advise on topics of need for their community, study design and formulation, participant recruitment, and study implementation. They have engaged in intervention design, advised researchers and PBRN staff, reviewed surveys, developed Web site content, improved toolkit design, participated in BCTs, and developed guides for people living with diabetes ${ }^{29}$ and chronic pain. ${ }^{30,31}$

Ongoing Engagement. Since 2010, the PAC has met bimonthly to discuss current and future projects. The group often has guests attend meetings to share new opportunities or provide input on topics of interest. During the 2018 ECER Conference, the PAC presented a poster to attendees from across Colorado. Their poster highlighted their nearly 10 -year history, and why it is important to involve patients throughout a project's life cycle.
This group has built strong relationships and truly value everyone's opinions. In a 2017 meeting, CaReNet staff asked the PAC their thoughts on participation; the following are some responses. The PAC feels the University staff honors their opinions and "will not bring them down a path that leads nowhere." The PAC enjoys the process of working on and planning projects, and they feel they are needed, taken seriously, and can discuss topics openly despite their differing perspectives. One member stated that we have "stimulating conversations and topics," while another said she stays around to "see the products at the end of the project." One drawback shared is that this type of engaged research takes extra time, and therefore results and products are occasionally shared slower than they would like. Overall, PAC members continue to be involved because of the good friendships and experiences: "this group just clicks"; the meetings are never boring: "engagement needs to be fun"; and the food is always good: "you should break bread together regularly."

Impact. The PAC has served in numerous project roles and PBRN operations, and have become valued coinvestigators on numerous occasions. Presently, 3 of the PAC members serve as patient advisors on other federally funded projects, and 2 members serve on both the NAPCRG PBRN Planning Committee and NAPCRG Patient and Clinician Engagement Board. ${ }^{32,33}$

\section{Colorado Children's Outcomes Network's Network Advisory Board}

History and Origins. Colorado Children's Outcomes Network (COCONet) is a pediatric PBRN spanning the state of Colorado. The Network Advisory Board (NAB) was developed through a structured Patient-Centered Outcomes Research Institute Engagement Award that developed parent, patient, and stakeholder engagement in pediatric health outcomes research, specifically within the footprint of this pediatric PBRN. ${ }^{34}$

NAB Member Recruitment. The foundation for the COCONet NAB was laid through extensive qualitative interviews about pediatric health priorities, conducted with parents and stakeholders in the network in 2015 and 2016. ${ }^{34}$ After each interview, COCONet staff gathered interest in continuing involvement with the network.

Advisors worked with COCONet staff to define $\mathrm{NAB}$ composition and determine potential partic- 
ipants to span varied parenting roles and professional expertise. The team also identified additional stakeholders to round out the NAB's composition. COCONet staff discussed with each participant the role of the $\mathrm{NAB}$ and the commitment members were making.

The NAB first met in Spring 2016 with 15 members, including 3 researchers, 11 parents, and 1 advocacy organization representative. Members represented professional backgrounds relevant to child health and wellbeing. In a NAB survey, 1 member stated they like the group structure because, "Being involved with COCONet advisory group has allowed me to connect with other organizations not only across the state but regionally to discuss best practices and trends in community health."

NAB Engagement in Research Projects. The NAB first reviewed findings from recruitment interviews and created a top 3 health issues list to pursue in working groups. ${ }^{34}$ These issues included training parents and teens as advocates to improve health outcomes, access to and availability of mental health care, and immunization refusal. COCONet priorities and directions have remained around these top 3 issues with the support and guidance of the NAB. Members have participated in working groups and designed research projects and aims for grant proposals. In addition, both working group and $\mathrm{NAB}$ members are included as project team members.

NAB members share their involvement in research means they have a say in how the pediatric health system serves kids and families. An ongoing discussion is how COCONet can serve as a nexus for the many aspects of child health such that families can support holistic health and wellness for their kids across specific health topics or diagnoses.

NAB members stay engaged because of passion about solving problems in pediatric health care and are excited to have a voice in the process. One NAB member stated, "My time with COCONet made it possible for my husband and I to play an active role in setting pediatric research priorities through an innovative process that was novel to us both." NAB members appreciate that leadership seeks input and time only when there are important matters for discussion.

Ongoing Engagement. NAB members are included in grant submissions and are paid when project-based funding is available. The NAB meets each quarter and focuses meetings on current and developing projects. Meetings address issues and topics of interest, as well as future goals. The 3 $\mathrm{NAB}$ priority topics have resulted in numerous grant proposals. Both the NAB and working groups continue to engage in projects and guide future priority selection.

Impact. Members of COCONet's NAB traveled to Bethesda, MD to present a workshop to other PBRNs regarding how patients can be involved in research processes. One presenting member stated the most fun part of their involvement in the NAB "was the opportunity to present this process, and the research priorities that emerged, during the 2017 Annual PBRN Conference.”

\section{Partners Engaged in Achieving Change in Health's Regional Advisory Board}

History and Origins. Partners Engaged in Achieving Change in Health (PEACHnet) is actively forming a Regional Advisory Board (RAB) using lessons learned from the other 3 SNOCAP advisory groups. The RAB will be composed of stakeholder groups including patients, health care workers, and community members from various organizations. This group will include 10 to 12 people and will meet monthly starting in July 2019. The name, "Regional Advisory Board," is being used to emphasize that PEACHnet includes practices and communities across a geographic region.

As of May 2019, 12 introductory meetings have occurred across Western Colorado. These meetings were attended by health care providers, office staff, social service agency staff, and community members. The RAB concept was introduced and participants shared that makeup should include individuals from each community and also people of diverse backgrounds. PEACHnet staff has started to meet with interested community members to discuss participation and expectations, PBRN advisory group structure, and participation requirements.

Participants are compensated for their planning time. The RAB plans to invite new members as founding members eventually leave. In the first year, PEACHnet plans to develop rules of governance that will specify terms of service and recruitment structure for new members in the future.

RAB Engagement in Research Projects. The initial focus of engagement activities includes intro- 
ducing interested stakeholders to the concepts of practice-based and community engaged research, followed by a series of topic generating meetings. Interest is also sought through participation in current PEACHnet projects: 1) the intersection of diabetes, obesity, and mental health, and 2) pragmatic trial of 2 models of diabetes group visits.

\section{Discussion}

SNOCAP recognizes the need to regularly assess priorities of PBRN partners to maintain relevance of our research. ${ }^{35}$ SNOCAP advisors ensure that the design, conduct, analysis, and dissemination of research are grounded in the needs of patients and communities. Patient and community advisors can be effective and invaluable research partners or coinvestigators but must be approached as equals. Advisory groups codrive the work along with the research team: it is a bidirectional partnership. These 4 cases show how Colorado PBRNs have worked through challenges to their advisory groups up for long-term success.

PBRN advisory groups take on various forms and function; however, all require long-term commitment and collaboration from both academic and community partners, driven by a desire to improve health. Across SNOCAP advisory groups, general similarities include staffing structure and leadership communication; coinvestigator roles and appropriate compensation when funding allows; structured meetings based on needs determined by both PBRN staff and advisory group members; and advisors integrally involved in decision making, especially when prioritizing research topics. Advisors require time and attention from PBRN staff to build relationship, trust, and respect. Compensation rates differ by PBRN (Table 2). Regular and transparent discussions regarding compensation are crucial. Generally, advisors are compensated during active projects and when funding lapses or the group is between funded projects, individual members must gauge their interest in continuing work at a lower or unpaid rate.

\section{Lessons Learned}

We want to share 6 lessons SNOCAP has learned along the way regarding membership, relationships, relevance, care and feeding, listening, and showing up.

\section{Membership}

Advisory group members are true community members and patients, or "free-range humans" as we like to say; they are not career researchers or physicians. This provides our PBRNs with authentic contributions, unencumbered by years of accumulated research jargon, clinical terminology, or expectations for academic publication or extramural funding. Members tend to speak freely, in their own words. A note is that individual members do not necessarily "represent" the community or practice they are from; instead they have expertise at living in a certain environment. It can be important to screen potential new members to ensure they do not have an agenda in place. Lastly, it is important to have diverse voices, expertise, and lived experiences at the table.

\section{Relationships}

Effective and impactful engagement requires personal relationships. This means spending time interacting both as advisory group members, but more importantly as individuals. Strive to personally know each member: their family, work, and hobbies to strengthen bonds within and among the group. These relationships will support the authenticity and sustainability of the work, and often evolve into meaningful friendships.

\section{Relevance}

Advisory groups support the relevance of practicebased research for both community and patients. These groups change the priorities of PBRNs and the projects in which they engage. Colearning about health issues is a great way for both researchers and community members to create relevance. Members have stated that being involved with this work has increased trust in research and has given them a broader outlook on health topics.

\section{Care and Feeding}

Advisory group work is more than regular meeting times and activities. PBRN staff regularly work to build in additional communication and ask for input and feedback to keep the group engaged between face-to-face meetings. Literal "feeding" is key to these relationships as well. "Breaking bread," as mentioned previously, is an essential piece to ensuring productivity and continued relationship building. ${ }^{36-40}$ 


\section{Call-Out Box: Additional Patient Engagement Resources}

\section{COCONet NAB Report from PCORI Engagement Award ${ }^{34}$}

Dolor RJ, Campbell-Voytal K, Daly J, et al. Practice-based Research Network Research Good Practices (PRGPs): Summary of Recommendations. Clin Transl Sci 2015;8(6):638-646. ${ }^{43}$

Institute for Patient- and Family-Centered Care (IPFCC): Engaging Patient and Family Advisors in Research. $^{44}$

\section{Listening}

Epictetus said, "We have 2 ears and 1 mouth so that we can listen twice as much as we speak." For infrastructure to endure and decision making to be collaborative, researchers must listen to each voice and incorporate their ideas into research. By engaging in a process of listening, reflecting, and listening again, PBRN researchers can ensure that the abovementioned values of advisory groups are effectively incorporated into this work. The HPRN C.A.C shares that after a colon cancer prevention project, the research team planned to publish work in journals and newspapers. The C.A.C. felt dissemination should instead include community discussion. After many conversations, the C.A.C. persisted, and together the research team and C.A.C. presented findings at local health fairs and community events.

\section{Showing Up}

Being fully present and active in discussions demonstrates commitment and interest. Engagement is not a box to check. Being present means spending time with people in their environment, inviting them to spend time in yours, and fully sharing the bidirectional partnership.

\section{Limitations}

This article shares the history of advisory groups in 1 PBRN consortium in 1 state. PBRN staff are employed by the same University. While these characteristics could prove to be limitations, here you will find a combined $35+$ years of experience working with such groups.

Depending on the makeup of the advisory group, bylaws, member agreements, or other official documentation may be required, which we do not report on here as it is out of the scope of this article. SNOCAP advisory groups have instead chosen to receive essential human subjects training and adhere to the Belmont Report ${ }^{17,41}$; however, this may or may not be required depending on a formal determination of engagement in research.

\section{Conclusion}

In our experience supporting this type of research, engagement works but requires supporting infrastructures. ${ }^{42}$ Advisory groups represent an essential complement to traditional research, showing engagement going beyond basic participation in research. Authentic engagement must be bi-directional and appreciative of all voices; this allows the research to focus on the needs of our patients and communities.

We would like to first acknowledge all current, former, and future SNOCAP advisory group members; current members whom are listed below. We would also like to thank Elizabeth Staton for her careful review of this manuscript.

High Plains Research Network Community Advisory Council Members: Christopher Bennett, Kaitlin Bennett, JC Carrica, Fred Crawford, Ashley Espinoza, Maret Felzien, Michael Garcia, Sandi Garcia, Connie Haynes, Garry Haynes, Michael Hernandez, Ned Norman, Mary Rodriquez, Norah Sanchez, Sergio Sanchez, Kathryn Winkelman, Steve Winkelman.

Colorado Research Network Patient Advisory Council Members: Esther Cancella, Kathy Chaten, Kenneth Dailey, Marcia Dailey, Anniece Johnson, Charles Leali, Linda Leali, Paul Merrow, Sally Merrow, Genevieve Smith, Jim Smith, Jo Smith, Michele Wheeler.

Colorado Children's Outcomes Network's Network Advisory Board Members: Cody Belzley, Elizabeth Bruno, Natalie Crump, Sean Crump, Maret Felzein, Liz Houston, Elaine Morrato, Ashley Neiderhauser, Kelly Stahlman, Jodi Walker, Judy Zerzan.

Partners Engaged in Achieving Change in Health Professional Research Assistant: Elena Broaddus, MSPH, PhD.

To see this article online, please go to: http://jabfm.org/content/ 32/5/663.full.

\section{References}

1. Westfall JM, Fagnan LJ, Handley M, et al. Practicebased research is community engagement. J Am Board Fam Med 2009;22:423-427.

2. Balazs CL, Morello-Frosch R. The three R's: how community based participatory research strengthens 
the rigor, relevance and reach of science. Environ Justice 2013;6(1).

3. Balint E. The possibilities of patient-centered medicine. J R Coll Gen Pract 1969;17:269-276.

4. Saha S, Beach MC, Cooper LA. Patient centeredness, cultural competence and healthcare quality. J Natl Med Assoc 2008;100:1275-1285.

5. Wallerstein N, Duran B. Community-based participatory research contributions to intervention research: the intersection of science and practice to improve health equity. Am J Public Health 2010; 100(Suppl 1):S40-S46.

6. Schmittdiel JA, Grumbach K, Selby JV. Systembased participatory research in health care: an approach for sustainable translational research and quality improvement. Ann Fam Med 2010;8:256259.

7. Hahn DL, Hoffmann AE, Felzien M, LeMaster JW, $\mathrm{Xu}$ J, Fagnan LJ. Tokenism in patient engagement. Fam Pract 2017;34:290-295.

8. IAP2. IAP2 spectrum of public participation. 2018. Available from: https://www.iap2.org/page/pillars. Accessed May 30, 2019.

9. Westfall JM, VanVorst RF, Main DS, Herbert C. Community-based participatory research in practice-based research networks. Ann Fam Med 2006; $4: 8-14$.

10. Macaulay AC, Nutting PA. Moving the frontiers forward: incorporating community-based participatory research into practice-based research networks. Ann Fam Med 2006;4:4-7.

11. Tapp H, Dulin M. The science of primary healthcare improvement: potential and use of communitybased participatory research by practice-based research networks for translation of research into practice. Exp Biol Med (Maywood) 2010;235:290299.

12. High Plains Research Network. High Plains Research Network YouTube Channel. 2019. Available from: https://www.youtube.com/channel/UCBo fdYsXJDLdpLY59S9SabQ. Accessed January 5, 2019.

13. Westfall JM, Van Vorst RF, McGloin J, Selker HP. Triage and diagnosis of chest pain in rural hospitals: implementation of the ACI-TIPI in the High Plains Research Network. Ann Fam Med 2006;4:153-158.

14. Hicks PC, Westfall JM, Van Vorst RF, et al. Action or inaction? Decision making in patients with diabetes and elevated blood pressure in primary care. Diabetes care 2006;29:2580-2585.

15. Felzien M, Zittleman L, Westfall JM. Farming, ranching, research: patient engagement on the High Plains. J Gen Intern Med 2016;31:3-4.

16. Westfall JM, Ingram B, Navarro D, et al. Engaging communities in education and research: PBRNs, AHEC, and CTSA. Clin Transl Sci 2012;5:250-258.

17. Westfall JM, Zittleman L, Felzien M, Ringel M, Lakin A, Nease D. Institutional review board train- ing when patients and community members are engaged as researchers. Fam Pract 2017;34:301-304.

18. Sand J, Felzien M, Haeme R, Tapp H, Derkowski D, Westfall JM. The North American Primary Care Research Group's Patient and Clinician Engagement Program (PaCE): Demystifying patient engagement through a dyad model. Fam Pract 2017;34:285-289.

19. Norman N, Cowart S, Felzien M, et al. Testing to prevent colon cancer: how rural community members took on a community-based intervention. Ann Fam Med 2013;11:568-570.

20. The High Plains Research Network Community Advisory Council. Supplemental Case Report. Community involvement in a practice based research network. 2006. Available from: http://www.annfammed. org/content/suppl/2006/02/08/4.1.8.DC1/Westfall_ appendix_corr.new.pdf. Accessed May 30, 2019.

21. Westfall JM, Zittleman L, Felzien M, et al. Reinventing the wheel of medical evidence: how the boot camp translation process is making gains. Health Aff (Millwood) 2016;35:613-618.

22. Van Vorst RF, Araya-Guerra R, Felzien M, et al. Rural community members' perceptions of harm from medical mistakes: a High Plains Research Network (HPRN) study. J Am Board Fam Med 2007; 20:135-143.

23. Norman N, Bennett C, Cowart S, et al. Boot camp translation: a method for building a community of solution. J Am Board Fam Med 2013;26:254-263.

24. Westfall JM, Zittleman L. Quandaries in authorship. Prog Community Health Partnersh 2018;12:117120.

25. Allison C, Zittleman L, Ringel M, et al. Translating the medical home into patient-centred language. London J Prim Care (Abingdon) 2014;6:124-130.

26. Parnes B, Niebauer L, Holcomb S, et al. Provider deferred decisions on hemoglobin A1c results: a report from the Colorado Research Network (CaReNet) and the High Plains Research Network (HPRN). J Am Board Fam Med 2006;19:20-23.

27. Parnes BL, Main DS, Dickinson LM, et al. Clinical decisions regarding $\mathrm{HbA1c}$ results in primary care: A report from CaReNet and HPRN. Diabetes Care 2004;27:13-16.

28. Goodman LA. Snowball sampling. Ann Math Statist 1961;32:148-170.

29. Kwan BM, Jortberg B, Warman MK, et al. Stakeholder engagement in diabetes self-management: patient preference for peer support and other insights. Fam Pract 2017;34:358-363.

30. Managing Diabetes. 2017. Available from: https:// connectiontohealth.org/health-tips/colorado/ managing-diabetes. Accessed January 25, 2019.

31. Testing the appreciative inquiry and boot camp translation methods for identifying and sharing local solutions to healthcare issues. 2019. Available from: https://www.pcori.org/research-results/2013/testing- 
appreciative-inquiry-and-boot-camp-translationmethods-identifying-and. Accessed January 25, 2019.

32. Norman N, Wolff C, Borcher R, Felzien M, Westfall J. NAPCRG's Patient and Clinician Engagement $(\mathrm{PaCE})$ project: engaging patients and providers in patient-centered outcomes research. Available from: https://www.napcrg.org/media/1409/plenaryii.pdf. Accessed May 30, 2019.

33. (NAPCRG) NAPCRG. 2018 NAPCRG Practicebased Research Network Conference Conference Program. 2018. Available from: https://www.napcrg.org/ media/1487/18-pbrn-program.pdf. Accessed May 30, 2019.

34. Brewer S, O'Leary S. Engaging parents and stakeholders in patient-centered pediatric research and research agenda setting. A guide for practice-based research networks. 2017. Available from: http://www. ucdenver.edu/academics/colleges/medicalschool/ programs/ACCORDS/sharedresources/education/ Documents/COCONet\%20link\%201_4.18.18.pdf. Accessed January 23, 2019.

35. Fisher M, Brewer S, Holtrop JS, et al. Returning to the original vision of practice-based research networks: setting research priorities from the ground up. J Am Board Fam Med [in press].

36. Simon C, Mosavel M. Community members as recruiters of human subjects: ethical considerations. Am J Bioeth 2010;10:3-11.

37. Svara JH, Denhardt J. The connected community: local governments as partners in citizen engagement and community building. 2010. Available from:
https://icma.org/sites/default/files/301763_Community ConnectionsWhitePaper.pdf. Accessed January 25, 2019.

38. D'Alonzo KT. Getting started in CBPR: lessons in building community partnerships for new researchers. Nurs Inq 2010;17:282-288.

39. DePrince AP. Public good and the nexus of social justice, feminism, and Rock 'n' Roll. Journal of Higher Education Outreach and Engagement 2009;16.

40. Redding S, Murphy M, Sheley P. Handbook on family and community engagement. 2011. Available from: http://www.schoolcommunitynetwork.org/ downloads/FACEHandbook.pdf.

41. United States. National Commission for the Protection of Human Subjects of Biomedical and Behavioral Research. The Belmont report: ethical principles and guidelines for the protection of buman subjects of research. Bethesda, MD: Washington, DC: The Commission; for sale by the Superintendent of Documents, US Government Printing Office; 1978.

42. Nease DE Jr, Burton D, Cutrona SL, et al. "Our lab is the community": defining essential supporting infrastructure in engagement research. J Clin Transl Sci 2018;2:228-233.

43. Dolor RJ, Campbell-Voytal K, Daly J, et al. Practice-Based Research Network Research Good Practices (PRGPs): summary of recommendations. J Clin Transl Sci 2015;8:638-646.

44. Institute for Patient- and Family-Centered Care. Creating opportunities for pfas to serve on research teams. Available from: http://www.ipfcc.org/best practices/sustainable-partnerships/engaging/creatingopportunities.html. Accessed May 30, 2019. 